\title{
Anticorpos contra Beta2-Glicoproteína I, Autoimunidade e Aterosclerose ${ }^{(*)}$
}

\section{Antibodies to Beta2-Glycoprotein I, Autoimmunity and Atherosclerosis}

\author{
Aline Ranzolin ${ }^{(1)}$, Andrei Lotterman ${ }^{(1)}$, Jussara Bohn ${ }^{(1)}$, Carlos Alberto von Mühlen ${ }^{(2)}$ e Henrique Luiz Staub ${ }^{(3)}$
}

\section{RESUMO}

A beta2-glicoproteína I (beta2-gpI) é um cofator fosfolipídico com propriedades anticoagulantes. Inúmeras funções biológicas na via da coagulação são atribuíveis a este cofator. Os soros de pacientes com síndrome antifosfolipídica (SAF) freqüentemente reagem contra beta2-gpI em ensaios imunoenzimáticos. Por vezes, pacientes com diátese trombótica apresentam anticorpos antibeta2-gpI na ausência de outros anticorpos anti-fosfolípides (AAF). Mais recentemente, comprovou-se a presença da beta2-gpI na placa aterosclerótica. Nesta revisão, abordamos inicialmente as funções fisiológicas da beta2-gpI na via da coagulação. A seguir, revisamos a importância dos anticorpos anti-beta2-gpI em pacientes com SAF, outras diáteses trombóticas, lúpus eritematoso sistêmico (LES) e infecções. Por fim, o papel dos anticorpos anti-beta2-gpI na aterosclerose coronária e cerebral é também abordado.

Palavras-chave: beta2-glicoproteína I, anticorpos anti-beta2-gpI, síndrome antifosfolipídica, aterosclerose.

\section{ANTICORPOS ANTIFOSFOLÍPIDES E SÍNDROME ANTIFOSFOLIPÍDICA}

Os anticorpos antifosfolípides (AAF) compreendem um grupo de autoanticorpos de grande complexidade e heterogeneidade ${ }^{(1)}$. Os alvos-chave destes anticorpos são fosfolípides (FL) e cofatores fosfolipídicos da cascata da coagulação e das membranas celulares. As superfícies plaquetária e endotelial são alvos conhecidos de $\operatorname{AAF}^{(2)}$.

\begin{abstract}
Beta2-glycoprotein I (beta2-gpI) is a phospholipid cofactor with anticoagulant properties. A number of biological functions in the coagulation cascade have been attributed to this cofactor. Sera from patients with antiphospholipid syndrome (APS) frequently react to beta2-gpI in immunoassays. Occasionally, patients with thrombotic diathesis present anti-beta2-gpI antibodies in the absence of other antiphospholipid antibodies (APA). More recently, the presence of beta2-gPI in the atherosclerotic plaque has been proved. In this article, we initially approach the physiological functions of beta2-gpI in the coagulation cascade, and we also review the importance of anti-beta2gpI antibodies in patients with APS, systemic lupus erythematosus (SLE) and infections. Lastly, we focus the role of anti-beta2-gpI antibodies in coronary and cerebral atherosclerosis.
\end{abstract}

Keywords: beta2-glycoprotein I, anti-beta2-gpI antibodies, antiphospholipid syndrome, atherosclerosis.

Os AAF estão associados a infecções, neoplasias, uso de drogas e a uma diátese trombótica conhecida como síndrome antifosfolipídica $(\mathrm{SAF})^{(2,3)}$. A SAF é atualmente tida como a mais comum das diáteses trombóticas adquiridas do adulto jovem ${ }^{(1,3)}$. Os mecanismos pelos quais os AAF induzem trombofilia em pacientes com SAF são múltiplos. Estes mecanismos estão sumarizados na Tabela 1.

A caracterização clínico-laboratorial da SAF foi progressivamente aprimorada a partir da descrição original de $1986^{(4)}$.

\footnotetext{
* Serviço de reumatologia da Faculdade de Medicina da Pontifícia Universidade Católica do Rio Grande do Sul (PUCRS), Porto Alegre, RS. Recebido em $31 / 3 / 2003$. Aprovado, após revisão, em 12/8/2003.

1. Residente do serviço de reumatologia da Faculdade de Medicina da PUCRS.

2. Doutor em reumatologia, professor de reumatologia da Faculdade de Medicina da PUCRS.

3. Doutor em reumatologia, professor de reumatologia da Faculdade de Medicina da PUCRS e da Universidade Luterana do Brasil (ULBRA), Canoas, RS.

Endereço para correspondência: Henrique Luiz Staub. Serviço de reumatologia da Faculdade de Medicina da PUCRS. Av. Ipiranga 6690, sala 220, Porto Alegre, CEP 90610-000. E-mail: henriquestaub@terra.com.br
} 
TABELA 1

Mecanismos de aÇÃo dos AAF EM PACIENTES COM TROMBOFILIA ATRIBUÍDA A SAF ${ }^{(1-3)}$
1. Bloqueio da ação de $\mathrm{FL}^{*}$ no complexo ativador da protrombina
2. Inibição da ação de $F L$ na ativação do fator $X$
3. Inibição do efeito de $F L$ na geração de proteína $C$
4. Bloqueio da síntese de proteína $S$
5. Interferência no efeito da heparina sobre a antitrombina III
6. Ação sobre $\mathrm{FL}$ da membrana plaquetária
7. Efeito antiprotrombina na superfície plaquetária
8. Efeito inibitório sobre a ação anticoagulante da beta2- glicoproteína I
9. Inibição da ação anticoagulante da anexina V na placenta e endotélio
10. Diminuição da síntese de prostaciclina pelas células endoteliais

*FL: fosfolípides

Os critérios atualmente aceitos para classificação da SAF datam do consenso de Saporo de 1999(5). Tromboses venosas profundas, isquemia de artérias cerebrais e morbidade obstétrica são os achados mais frequientes da doença ${ }^{(4-6)}$.

Embora descrita inicialmente em pacientes com lúpus eritematoso sistêmico (LES) ${ }^{(4)}$, a forma primária da SAF é reconhecida desde $1989^{(6)}$.

Os critérios laboratoriais para o diagnóstico da SAF, de acordo com o consenso de 1999, fundamentam-se em ensaios de coagulação (anticoagulante lúpico) e no imunoensaio enzimático (ELISA) para anticorpos anticardiolipina (aCL). Enquanto a padronização dos testes para detecção do AL é ainda problemática, o ELISA, que detecta anticorpos IgG/ IgM aCL, é internacionalmente aceito desde $1987^{(7)}$.

A classificação dos AAF, no entanto, é complexa e inclui uma pletora de anticorpos contra outros FL e contra cofatores fosfolipídicos. Estes anticorpos não fazem parte dos critérios laboratoriais para $\mathrm{SAF}^{(5)}$. Entretanto, são eventualmente encontrados em pacientes com tromboses, associadamente ou não aos AAF "clássicos" (AL e anticorpos aCL) $)^{(1-3)}$. Neste contexto, devem ser citados os anticorpos contra outros FL aniônicos, contra o FL neutro fosfatidiletanolamina (FE) e contra os cofatores anexina $V$, protrombina e beta2-glicoproteína I (beta2-gpI).

Nesta revisão, abordaremos os aspectos atinentes aos anticorpos contra o cofator fosfolipídico beta2-gpI. A importância destes anticorpos em pacientes com tromboses é detalhadamente discutida. O papel dos anticorpos anti-beta2-gpI no processo aterosclerótico é também abordado.

\section{BETA2-GPI E ANTICORPOS ANTI-BETA2-GPI}

\section{BETA2-GPI. FUNÇÕES BIOLÓGICAS}

A proteína plasmática beta2-gpI foi originalmente isolada em $1961^{(8)}$. O gene da beta2-gpI humana é codificado no cromossomo $17^{(9)}$.

O corrente interesse pelo estudo de anticorpos antibeta2-gpI decorre das seguintes informações: a) beta2-gpI é alvo de anticorpos aCL ${ }^{(9-11)} ;$ b) o uso de beta2-gpI como imunógeno em modelos animais gera anticorpos aCL, anticorpos anti-beta2-gpI e SAF ${ }^{(12,13)}$. Recentemente, tolerância oral com baixas doses de beta2-gpI foi obtida em camundongos $\mathrm{BALB} / \mathrm{c}$ imunizados com o antígeno ${ }^{(14)}$.

A beta2-gpI (ou apoliproteína $\mathrm{H}$ ) é cofator fosfolipídico com características anticoagulantes naturais. É um polipeptídeo de 50 kilodaltons $(\mathrm{kDa})$, altamente glicosilado. Sua cadeia única contém 326 aminoácidos. Cinco domínios, de cerca de 60 aminoácidos cada, podem ser identificados na molécula ${ }^{(15)}$.

A Figura 1 mostra a conformação molecular da beta2-gpI bovina.

A seqüência de aminoácidos CKNKEKKC, localizada no quinto domínio, é o sítio de ligação da beta2-gpI com FL aniônicos. O sítio de ligação de AAF com a beta2-gpI, no entanto, ainda é matéria de discussão ${ }^{(15)}$.

À beta2-gpI é atribuída ação inibitória na ativação do fator XII (ativação por contato) na via da coagulação. A molécula contribui, em paralelo, para a ativação da proteína $\mathrm{C}$ da fibrinólise $^{(15)}$ e interage com a heparina ${ }^{(16)}$.

Além disso, a beta2-gpI parece inativar o complexo ativador da protrombina ao interagir com FL de carga negativa, possivelmente na superfície plaquetária. Os efeitos da beta2-gpI sobre a cascata da coagulação são aparentemente desregulados por $\operatorname{AAF}^{(15,17)}$.

A agregação plaquetária e a conversão da protrombina em trombina são também bloqueados na presença de beta2-gpI ${ }^{(18)}$. A beta2-gpI inibe a geração de fator Xa por plaquetas ${ }^{(19)}$.

Segundo Arnout et al., o efeito de AL (aumento dos tempos de coagulação FL-dependentes) atribuído aos anticorpos anti-beta2-gpI é dependente da formação de complexos binários que incluem anticorpos anti-beta2-gpI e antígeno em superfícies contendo $\mathrm{FL}^{(20)}$.

De interesse, anticorpos anti-beta2-gpI poderiam se ligar, in vivo, à beta2-gpI disponível na membrana de células em apoptose. A opsonização de células apoptóticas por anticorpos anti-beta2-gpI facilita a fagocitose dos corpos apoptóticos por macrófagos ${ }^{(21)}$. 


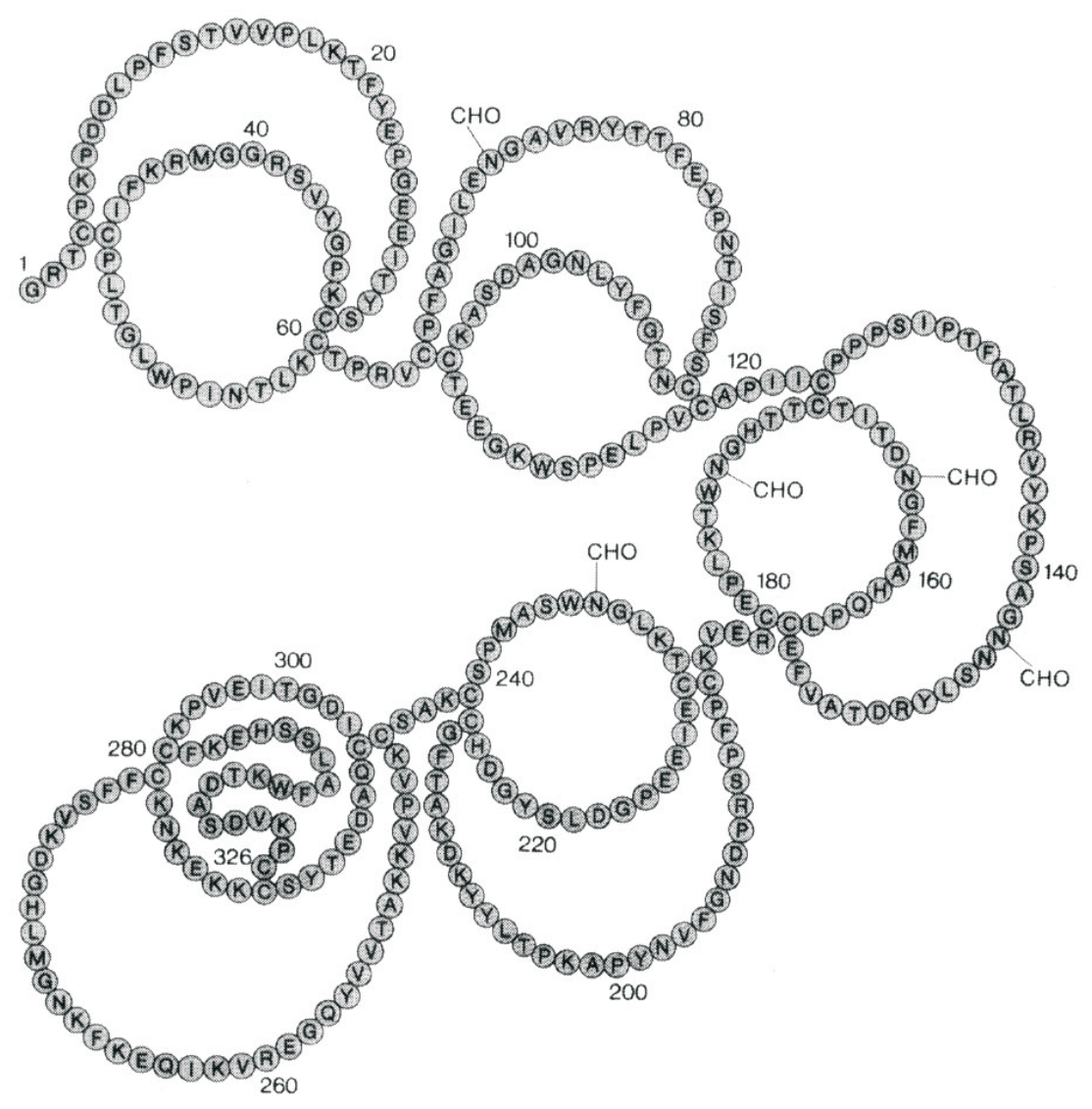

FiguRA 1 - Estrutura molecular da beta2-gpI bovina com seus cinco domínios ${ }^{(15)}$.

O teste do veneno de víbora de Russel (RVVT) compreende um dos testes de coagulação utilizados para confirmação de AL. Anticorpos anti-beta2-gpI são responsáveis pelo prolongamento do RVVT em ensaios de coagulação. De interesse, Galli et al., além de confirmarem o "perfil RVVT" dos anticorpos anti-beta2-gpI, reportaram que os mesmos seriam trombogênicos por induzirem resistência ao efeito da proteína $\mathrm{C}$ sobre o fator $\mathrm{V}^{(22)}$.

\section{ANTICORPOS ANTI-BETA2-GPI}

Os anticorpos contra beta2-gpI reconhecem o alvo fundamentalmente em superfícies celulares ou quando o cofator está ligado a FL. Biasiolo et al. comprovaram estes achados como característicos de pacientes com SAF. Os complexos imunes anti-beta2-gpI de pacientes com outras doenças auto-imunes são detectados livremente no plasma ${ }^{(23)}$.
De acordo com Mason et al., soros de pacientes com SAF reagiram em ELISA contra beta2-gpI e anticorpos aCL. Os soros também exibiram reatividade contra um antiidiotipo obtido de uma IgM monoclonal com atividade aCL. A reação humoral contra este anti-idiotipo foi característica de soros de pacientes com $\mathrm{SAF}^{(24)}$.

A avidez dos anticorpos de pacientes com SAF pela cardiolipina (CL) em placas de ELISA é consideravelmente maior quando diluentes que utilizam soro bovino a $10 \%$, fontes de beta2-gpI, são utilizados. É possível que a conformação bioquímica da CL seja modificada pela beta2-gpI, ou que os dois compostos formem um complexo antigênico, ou ainda que a beta2-gpI funcione como um antígeno de forma isolada ${ }^{(15,16,25)}$.

Sabidamente, anticorpos aCL policlonais ligam-se a beta2gpI somente em placas de poliestireno irradiadas, onde epitopos "críticos" da beta2-gpI podem ser expostos ${ }^{(25)}$. 
Nos dias de hoje, admite-se que a interação de beta2gpI com placas de poliestireno irradiadas, ou com CL, permite a exposição de epitopos fundamentais na molécula de beta2-gpI ${ }^{(26)}$.

Os testes de ELISA para detecção de anticorpos anti-beta2gpI utilizam placas irradiadas contendo beta2-gpI na ausência de $\mathrm{FL}^{(27)}$. As placas de poliestireno irradiadas contêm superficies oxidadas, o que facilita a ligação de anticorpos de baixa afinidade com a molécula nativa de beta2-gp ${ }^{(28)}$.

Uma vez que os anticorpos anti-beta2-gpI de pacientes com SAF são de baixa afinidade, a alta densidade de antígeno em placas de ELISA é de crucial importância no ensaio enzimático. A dimerização da beta2-gpI parece aumentar a capacidade de ligação dos anticorpos ${ }^{(29)}$.

Enquanto o ELISA para detecção de aCL utiliza beta2-gpI bovina, o ensaio enzimático específico para anti-beta2-gp1 usa beta2-gpI humana purificada ${ }^{(30)}$.

A forma de apresentação da beta2-gpI influencia fortemente a ligação dos anticorpos, com marcadas variações interindividuais. Anticorpos anti-beta2-gpI de pacientes com SAF podem reagir particularmente contra o antígeno bovino, ou contra ambos beta2-gpI bovina e humana. Os soros que se ligam a ambos os antígenos são mais freqüentemente aCL-positivos do que negativos ${ }^{(31)}$.

Segundo Santiago et al. ${ }^{(32)}$, um número apreciável de variáveis pode interferir na acuidade da detecção de anticorpos anti-beta2-gpI. As diversas técnicas de purificação da beta2-gpI originam diferenças qualitativas no antígeno, assim como geram concentrações não uniformes do mesmo.

Por sua vez, placas de poliestireno de origens diversas podem gerar diferenças na aderência do antígeno. Em conseqüência, a concentração final do antígeno pode não ser homogênea quando se compara diferentes ensaios ${ }^{(33)}$.

A partir de testes realizados em um laboratório em San Diego, EUA, iniciativas para padronização do ELISA para detecção de anticorpos anti-beta2-gpI foram levadas a termo em 1998. Os ensaios para os isotipos IgG/IgM/IgA geraram curvas lineares e de boa precisão. Duzentos e três controles sadios foram utilizados para a geração de intervalos de referência baseados em percentis. Em soros de pacientes com SAF, os três ensaios anti-beta2-gpI se correlacionaram adequadamente com os respectivos ensaios enzimáticos para detecção de $\mathrm{aCL}^{(34)}$.

De forma alternativa, Cucnik et al. sugeriram, em relato recente, que a determinação de anti-beta2-gpI em ELISA seja baseada em concentrações padronizadas de anticorpos monoclonais IgG e IgM. Os pontos de corte, no estudo, foram calculados a partir de resultados obtidos em 434 controles sadios ${ }^{(35)}$.
Ichikawa et al. produziram uma IgG monoclonal quimérica contendo uma região constante gama 1 de origem humana. O referido anticorpo reagiu contra CL e beta2-gpI de forma similar aos soros-padrões aCL e anti-beta2-gpIpositivos. Os autores sugerem que o referido anticorpo monoclonal possa ser de utilidade em uma padronização internacional do ensaio para IgG anti-beta2-gpI ${ }^{(36)}$.

A Tabela 2 apresenta os dados de Roubey et al. acerca da sensibilidade e da especificidade de anticorpos IgG antibeta2-gpI e aCL para o diagnóstico de $\mathrm{SAF}^{(37)}$.

De acordo com os dados de Roubey et al. para pontos de corte de 20 UI, o ensaio para IgG anti-beta2-gpI, embora menos sensível, foi mais específico que IgG aCL para o diagnóstico de $\mathrm{SAF}^{(37)}$.

Segundo dados de 1995, a soroprevalência de anticorpos anti-beta2-gpI por ELISA em controles sadios é de 0\%; em casos de LES sem AAF, é de 12\%; em pacientes com LES e AAF, é de 53\%; em casos de SAF primária, é de $72 \%{ }^{(38)}$.

Em estudo mais recente ${ }^{(39)}$, Bruce et al. avaliaram a prevalência de aCL e IgG/IgM/IgA anti-beta2-gpI em 133 indivíduos com doenças autoimunes e controles. Anticorpos anti-beta2-gpI (qualquer isotipo) foram observados em $34,9 \%$ dos casos de LES isolado, em 40,4\% dos casos de SAF associada ao LES e em $3 \%$ de controles sadios. O valor preditivo positivo (VPP) para SAF foi de 38,8\% para anticorpos anti-beta2 e de 50\% para IgG aCL. Os autores concluíram que a testagem de anti-beta2-gpI, embora útil em casos isolados, não aumentou a probabilidade do diagnóstico de SAF.

Helbert et al. procederam meta-análise para avaliar comparativamente três ensaios comerciais para aCL e um ensaio para anti-beta2-gpI. O estudo confirmou que o ensaio para anti-beta2-gpI é mais específico (embora menos sensível) que aCL para o diagnóstico de SAF. A melhor especificidade do ensaio para anti-beta2-gpI esteve fundamentada em sua performance usualmente positiva em pacientes ateroscleróticos e sua testagem geralmente negativa em infecções ${ }^{(40)}$.

TABELA 2

Sensibilidade E especificidade de Anticorpos IGG ANTI-BETA2-GPI E IGG ACL (ELISA) PARA O DIAGNÓSTICO DE SÍNDROME ANTIFOSFOLIPÍDICA (SAF) ${ }^{(37)}$

\begin{tabular}{ccc}
\hline & Anti-beta2-gpI & aCL \\
\hline Ponto de corte: 20 UI & & \\
Sensibilidade & $22 \%$ & $35 \%$ \\
Especificidade & $94 \%$ & $79 \%$ \\
\hline
\end{tabular}

UI: unidades internacionais 
Outros relatos também favorecem a idéia de que anticorpos anti-beta2-gpI humana detectados por ELISA sejam mais específicos do que aCL em pacientes com quadro clínico de $\operatorname{SAF}^{(41,42)}$.

Diferentemente, não mais que $50 \%$ dos pacientes com SAF aCL-positivos apresentaram anticorpos anti-beta2-gpI. Neste mesmo estudo ${ }^{(43)}$, uma eventual reação cruzada entre anticorpos anti-beta2-gpI e anticorpos contra LDL (low-density lipoprotein), previamente sugerida ${ }^{(4)}$, não foi confirmada.

Digno de nota, boa parte dos estudos sobre anticorpos contra beta2-gpI em ELISA incluíram IgG mas não outros isotipos de imunoglobulinas ${ }^{(41-44)}$. Além disso, a falta de padronização dos ensaios de fase sólida que detectam anticorpos contra beta2-gpI tem sido um obstáculo na análise crítica dos estudos clínicos.

\section{ANTICORPOS ANTI-BETA2-GPI E LÚPUS ERITEMATOSO SISTÊMICO (LES)}

Em pacientes com LES, a associação de anticorpos antibeta2-gpI com trombose tem sido extensivamente estudada. Recentemente, Santiago et al. demonstraram ausência de associação entre IgG anti-beta2-gpI e eventos trombóticos ou morbidade obstétrica em pacientes com LES $^{(32)}$.

De interesse, George et al. reportaram que a presença de anticorpos anti-beta2-gpI é útil para definir uma subpopulação de pacientes com LES propensa a desenvolver trombocitopenia ${ }^{(45)}$.

De acordo com um estudo de 1992, anticorpos antibeta2-gpI e AL ocorreram em $89 \%$ de pacientes com LES e trombose, enquanto aCL foi visto em $78 \%$ destes pacientes. Entre todos os casos aCL-positivos mas anti-beta2-gp1negativos, somente $6 \%$ tiveram tromboses. Assim, anticorpos anti-beta2-gp1 estiveram mais convincentemente associados à trombofilia que outros AAF nesta casuística ${ }^{(46)}$.

De acordo com Sanfilippo et al., anticorpos anti-beta2gpI foram mais prevalentes em pacientes com LES e SAF (62\%) que nas lúpicas aCL-positivas sem trombose. Os autores sugerem que estes auto-anticorpos funcionam como marcadores de tromboses no $\operatorname{LES}^{(47)}$.

Por outro lado, Tubach et al. reportaram que a ocorrência de IgG anti-beta2-gpI em 102 casos de LES, quase tão freqüente quanto a de aCL $(18,6 \%$ e $23 \%$ respectivamente), não aumentou a chance de diagnóstico de SAF. Outros isotipos anti-beta2-gpI não foram estudados. No referido relato, o AL se comportou como o melhor teste na identificação de casos de $\operatorname{SAF}^{(48)}$.

Em 76 pacientes com LES, oriundos da Índia, Shrivastava et al. reportaram que IgG anti-beta2-gpI, assim como aCL, estiveram associados à presença de convulsões mas não a outros eventos compatíveis com $\mathrm{SAF}^{(49)}$.

Aguirre et al. relatam, em 126 pacientes chilenos com LES, positividade para aCL (qualquer isotipo) de 30\%, enquanto a positividade para anti-beta2-gpI foi de $10 \%$. Embora houvesse uma boa correlação IgG aCL-IgG antibeta2-gpI, um número não desprezível de casos foi positivo para apenas um dos anticorpos. Nesta casuística, o ensaio para anticorpos anti-beta2-gp foi mais específico que aCL para o diagnóstico de $\mathrm{SAF}^{(50)}$.

Também digno de nota, Inanc et al. avaliaram longitudinalmente pacientes com LES e SAF; aCL, anti-beta2-gpI e antiprotrombina foram estudados. A maior parte dos pacientes com trombose teve teste positivo para IgG antibeta2-gpI, mas não para anticorpos antiprotrombina. Muitos dos casos positivos para IgG anti-beta2-gpI (predominantemente IgG2) foram negativos para aCL. Os níveis do antígeno beta2-gpI foram aumentados em alguns casos de SAF. Os autores inferem que a testagem de anti-beta2gpI pode ser útil na investigação de tromboses em casos de LES $^{(51)}$.

Os resultados de Sebastiani et al. em 574 casos de LES sugerem que a presença de IgG/IgM anti-beta2-gpI, ou títulos moderados/altos de IgG aCL, são fatores de risco para trombose em LES. Sensibilidade, especificidade e valores preditivos foram similares nos dois ensaios ${ }^{(52)}$.

Cucurull et al. avaliaram a prevalência, distribuição isotípica e associações clínicas de anticorpos anti-beta2-gpI e aCL em 160 pacientes da Colômbia e em igual número de pacientes espanhóis com LES. Na população colombiana, anticorpos anti-beta2-gpI e IgG aCL se correlacionaram com trombose, perdas fetais e trombocitopenia. Em espanhóis, as associações incluíram livedo reticularis, além de tromboses e morbidade gestacional. Nas duas populações, o ensaio para anti-beta2-gpI foi mais específico que $\mathrm{aCL}^{(53)}$.

De forma original, Gomez-Pacheco et al. avaliaram anticorpos anti-beta2-gpI e aCL antes, durante e depois do episódio trombótico em pacientes com LES. Todos os casos de LES com trombose foram positivos para anti-beta2-gpI, e um signicativo decréscimo das titulações do anticorpo foi observado durante o episódio oclusivo ${ }^{(54)}$.

Com relação ao isotipo IgA anti-beta2-gpI, é digno de nota o estudo de Tsutsumi et al. em 124 pacientes nipônicos com LES. Positividade para IgA anti-beta2-gpI foi vista em $25 \%$ dos casos. Houve associação significativa deste isotipo com tromboses. Os autores sugerem que IgA anti-beta2gpI seja incluída na avaliação de risco trombótico em pacientes com LES ${ }^{(55)}$. 
Os mesmos autores relatam, em outro estudo, uma baixa concordância IgA anti-beta2-gpI-aCL-IgA comparativamente ao paralelismo observado nos isotipos IgG/IgM; o achado sugere que IgA aCL e IgA anti-beta2-gpI compõem dois grupos de AAF com diferentes afinidades ${ }^{(56)}$.

Em relato de 2001, Bertolaccini et al. avaliaram, transversalmente, a prevalência de IgG/IgM/IgA anti-beta2-gpI, aCL e antiprotrombina em 134 casos de LES/SAF. Os autores concluíram que a testagem de anti-beta2-gpI e IgA aCL não aumentou a probabilidade do diagnóstico de $\mathrm{SAF}^{\left({ }^{57}\right)}$.

Em 100 pacientes de origem africana com LES, a prevalência de aCL e anti-beta2-gpI foi, respectivamente, de 33\% e 28\% (dados de Cucurull et al.). O isotipo IgA foi o mais freqüente em ambos os ensaios. Uma concordância entre os ensaios foi mais notada para o isotipo IgA. IgG aCL ocorreu em títulos baixos, o que talvez explique a baixa frequiência de trombose ${ }^{(58)}$.

Outra casuística incluiu 207 pacientes com LES, com testagem para todos os isotipos aCL e anti-beta2-gpI. Trombose arterial foi associada com IgG aCL, e TVP com IgA anti-beta2-gpI em análise multivariada. Houve correlação entre níveis de qualquer isotipo anti-beta2-gpI com IgG aCL. Uma associação entre títulos de IgA anti-beta2gpI com os outros dois isotipos anti-beta2-gpI foi observada. Os autores concluem que IgA anti-beta2-gpI pode ser de utilidade na identificação de tromboses em casos de $\operatorname{LES}^{(59)}$.

Pacientes com LES, com ou sem tromboses, foram estudados por Lakos et al. quanto à prevalência de todos os isotipos anti-beta2-gpI. Houve forte associação de IgA antibeta2-gpI com trombose venosa, valvulopatias, trombocitopenia, epilepsia e livedo reticularis. O isotipo IgG associou-se com tromboses e AL, enquanto IgM anti-beta2-gpI se associou com valvulopatia e trombocitopenia ${ }^{(60)}$.

O somatório de achados observados nos diversos relatos acerca do binômio IgA anti-beta2-gpI-tromboses no LES é, no mínimo, intrigante. Novos estudos, preferencialmente controlados e com análise multivariada, poderão definir mais claramente esta associação.

Dektov et al. argúem sobre a importância da testagem de IgG/IgM anti-beta2-gpI para a melhor caracterização da SAF. Quarenta e dois casos de SAF e 32 casos de LES sem trombose foram avaliados. Houve correlação positiva entre titulações de aCL e anti-beta2-gpI para ambos os isotipos. A especificidade para SAF foi de $91 \%$ para IgG anti-beta2-gpI e de 75\% para IgG aCL. Com relação ao isotipo IgM, as especificidades foram de, respectivamente, $87 \%$ e $81 \%$. A presença de AL concomitante à aCL e antibeta2-gpI identificou um grupo de pacientes com SAF primária severa. Os autores sugerem que o ensaio para antibeta2-gpI, embora mais específico do que aCL, não deveria substituir o último ${ }^{(61)}$.

Tektonidou et al. avaliaram quais possíveis combinações de achados iniciais na SAF teriam valor prognóstico em termos de novos eventos trombóticos. Pacientes que inicialmente cursaram com hemólise e anticorpos anti-beta2gpI foram os mais propensos à trombofilia futura ${ }^{(62)}$.

\section{ANTICORPOS ANTI-BETA2-GPI E MORBIDADE GESTACIONAL}

Alguns relatos merecem menção. De forma prospectiva, Faden et al. acompanharam 510 gestantes quanto à presença de $\mathrm{aCL}$, anti-beta2-gpI e complicações obstétricas. Anticorpos antibeta2-gpI e aCL foram detectados em 3,9\% e 1,6\%, respectivamente. Anticorpos anti-beta2-gpI estiveram associados à preeclâmpsia/eclâmpsia, mesmo na ausência de aCL. Os autores sugerem que anticorpos anti-beta2-gpI sejam testados nestas circunstâncias ${ }^{(63)}$.

Em interessante relato onde 90 mulheres com morbidade fetal prévia foram avaliadas, Franklin et al. observaram presença de AAF (aCL ou AL) em metade dos casos. Anticorpos anti-beta2-gpI foram observados em não mais que $22,2 \%$ dos casos AAF-positivos, e em apenas 2,2\% das pacientes AAF-negativas ${ }^{(64)}$.

Em estudo de caso controle, Gris et al. reportaram que a presença de IgG anti-beta2-gpI, assim como a de IgG antianexina $\mathrm{V}$, IgM anti-FE e AL, foram associadas com risco significante de perdas fetais em mulheres sem tromboses prévias. Além disso, estes marcadores se associaram à morbidade gestacional futura ${ }^{(65)}$.

Em estudo de Lynch et al., anticorpos anti-beta2-gpI, difererentemente de IgG aCL e IgG anti-FS, não foram preditivos para perdas fetais em uma coorte de 325 pacientes ${ }^{(66)}$.

De interesse, IgA anti-beta2-gpI foi detectada com mais freqüência em mulheres com abortamentos repetidos (mesmo naquelas com teste negativo para IgG aCL/AL) que em controles férteis ${ }^{(67)}$.

Os achados de Lee et al. revelaram associação de ambos aCL e anti-beta2-gpI com SAF, mas a testagem de anti-beta2gpI não foi vantajosa na identificação de pacientes com abortamentos ou perdas fetais aCL-negativos ${ }^{(68)}$.

\section{ANTICORPOS ANTI-BETA2-GPI E OUTRAS DOENÇAS TROMBÓTICAS}

Em 227 pacientes consecutivos com TVP ou embolia pulmonar (30\% dos quais com AAF), anticorpos anti-beta2gpI foram demonstrados em 8,4\% dos casos. De interesse, 
a presença destes anticorpos identificou um subgrupo de pacientes consideravelmente propensos a recorrências trombóticas ${ }^{(69)}$.

Em pacientes sob hemodiálise com trombose de acessos vasculares, a freqüência de anticorpos anti-beta2-gpI, diferentemente do que ocorreu com anticorpos contra o fator $\mathrm{V}$ bovino, não foi significativa ${ }^{(70)}$.

A prevalência de AAF em 54 pacientes com hipertensão pulmonar (primária ou secundária) foi recentemente avaliada por Martinuzzo et al. AL, níveis moderados/altos de aCL e anticorpos anti-beta2-gpI estiveram relevantemente associados a uma forma crônica, tromboembólica, de hipertensão pulmonar ${ }^{(71)}$.

Liozon et al. relataram completa ausência de anticorpos anti-beta2-gpI em 45 casos de arterite de células gigantes comprovados por biópsia; o achado contrasta com a prevalência relevante de aCL (51\%) nesta afecção ${ }^{(72)}$.

Koutroubakis et al. reportaram ocorrência significativa de anticorpos anti-beta2-gpI e de aCL em pacientes com doença inflamatória intestinal (colite ulcerativa e doença de Crohn) com relação aos controles. Não houve associação dos anticorpos com tromboses nestas entidades, entretanto ${ }^{(73)}$.

Anticorpos anti-beta2-gpI não foram observados em nenhum caso de doença de Behçet; interessantemente, 25\% dos casos foram aCL-positivos. A presença de $\mathrm{aCL}$ não se associou à trombofilia nestes pacientes ${ }^{(74)}$.

\section{ANTICORPOS ANTI-BETA2-GPI E INFECÇÕES}

Embora o soro de pacientes com infecções geralmente seja desprovido de atividade anti-beta2-gpI ${ }^{(21)}$, o assunto é matéria de debate.

Um grupo de autores reportou que soros de pacientes com sífilis, tuberculose e infecção por Klebsiella, passíveis de apresentarem aCL circulantes respectivamente em $6 \%$, $5 \%$, e $64 \%$ das vezes, geralmente não reagem contra beta2gpI em ELISA. Os dados reforçam a noção de que AAF em doenças infecciosas são, via de regra, anticorpos aCL desprovidos de atividade anti-beta2-gpI e usualmente não-trombogênicos ${ }^{(21,96)}$. No entanto, teste positivo para anticorpos anti-beta2-gpI foi rerportado em 7,4\% dos pacientes HIV$\operatorname{positivos}^{(75)}$.

Digno de nota, Santiago et al. recentemente relataram a presença de anticorpos anti-beta2-gpI em pacientes com leptospirose, sífilis e kala-azar ${ }^{(76)}$.

Além disso, $57 \%$ dos pacientes com hanseníase reagiram fortemente contra beta2-gpI, com grande predomínio de $\operatorname{IgM}^{(77)}$.

\section{ANTÍGENOS DE HISTOCOMPATIBILIDADE E ANTICORPOS ANTI-BETA2-GPI}

Alguns haplótipos do sistema de antígenos leucocitários humanos (HLA) parecem predominar em pacientes com anticorpos anti-beta2-gpI. Usando tecnologia molecular, Loannidis et al. reportaram, em 67 pacientes gregos com SAF (54 dos quais com anticorpos anti-beta2-gpI), uma prevalência aumentada dos haplótipos HLA DQA1 03 e HLA DRB1*1302-DQB1*0604(78).

Em uma casuística européia de 577 casos de LES, a presença de anticorpos anti-beta2-gpI foi associada mais intensamente ao haplótipo HLA DRB1*0402; aCL, além de associados a HLA DR4, o foram também com o haplótipo DR $7^{(79)}$.

Arnett et al., por sua vez, relataram que o alelo HLA DQB1*0302, tipicamente pesquisado em haplótipos DR4, foi associado com a presença de anticorpos antibeta2-gpI em LES/SAF, especialmente em indivíduos de origem mexicana. HLA DR53 foi visto com freqüência aumentada em americanos de origem mexicana, mas não em caucasóides ${ }^{(80)}$.

\section{ANTICORPOS ANTI-BETA2-GPI E ATEROSCLEROSE}

$\mathrm{Na}$ aterosclerose, a infiltração da parede arterial por macrófagos e células musculares lisas é acompanhada da placa ateromatosa, cujo centro necrótico é circundado por deposição de colesterol ${ }^{(81)}$.

A aterosclerose deve ser analisada em contexto multifatorial. Sua patogênese parece se estender de fatores de risco conhecidos (hipertensão arterial, diabetes melito, tabagismo, hipercolesterolemia) até fenômenos de auto-imunidade ${ }^{(81,82)}$.

A perpetuação de fatores de risco como hipertensão arterial sistêmica (HAS) e hipercolesterolemia parece, de fato, induzir fenômenos de auto-imunidade. O endotélio ativado é capaz de secretar adesinas e proteínas de choque térmico (Hsp). A adesão de macrófagos vacuolizados e a migração de células musculares lisas culminam com a formação de ateromas ${ }^{(81,82)}$.

Os relatos que associam beta2-gpI, anticorpos anti-beta2gpI, anticorpos contra lipoproteínas e aterosclerose são dignos de nota. Em 1994, um grupo de autores demonstrou que aCL poderiam reagir cruzadamente com beta 2 -gpI e LDL oxidado $^{(44)}$. Estes achados não foram confirmados quatro anos depois, quando ausência de reatividade cruzada entre anticorpos anti-beta2-gpI e anti-LDL oxidado foi reportada em casos de $\operatorname{SAF}^{(43)}$.

Romero et al. estudaram o significado da presença de anticorpos anti-beta2-gpI e anti-LDL oxidado por ELISA em lúpicas com ou sem SAF. Anticorpos IgG anti-beta2- 
gpI, mas não anti-LDL oxidado, associaram-se à trombose arterial nesta casuística ${ }^{(83)}$.

Alternativamente, Amengual et al. reportaram que anticorpos anti-LDL oxidado ocorreram em 22\% de 107 casos de SAF, dado significante com relação aos controles. Houve associação deste marcador com tromboses arteriais, mas não venosas. Não houve correlação entre presença de anticorpos anti-LDL oxidado e anticorpos anti-beta2-gpI/aCL ${ }^{(84)}$.

A freqüência de anticorpos contra uma lipoproteína modificada por malondialdeído (MDA-Lpa) foi recentemente investigada por Romero et al. em 104 casos de SAF. A prevalência deste anticorpo foi de 37\%; aCL e anti-beta2-gpI foram detectados, respectivamente, em 64\% e 46\% dos casos. Não houve correlação entre presença de anticorpos contra MDA-Lpa e aCL/anti-beta2-gpI. A presença de anti-MDA-Lpa na SAF sugere um papel para fenômenos oxidativos nesta afecção ${ }^{(85)}$.

A relação da beta2-gpI com aterosclerose é assunto de grande interesse em anos recentes. George et al. reportaram presença abundante de beta2-gpI em placas ateroscleróticas humanas. A transição entre as regiões média e íntima das placas, bem como o subendotélio, foram ricos na expressão da molécula. A contiguidade com linfócitos CD4+ sugere que a bete2-gpI pode ser alvo de reação auto-imune na placa aterosclerótica ${ }^{(86)}$.

A indução de aterosclerose em camundongos deficientes em receptores de LDL após imunização com beta2-gpI foi recentemente demonstrada. Todos os animais imunizados desenvolveram altos títulos de anticorpos anti-beta2-gp ${ }^{(87)}$.

De acordo com Afek et al., camundongos deficientes em apoliproteína $\mathrm{E}$ tiveram o processo aterosclerótico acelerado após imunização com beta2-gpI. O efeito proaterogênico da imunização com beta2-gpI foi mantido independentemente de hipercolesterolemia ${ }^{(88)}$.

\section{ANTICORPOS ANTI-BETA2-GPI E ATEROSCLEROSE CORONÁRIA}

A relação entre AAF e infarto agudo do miocárdio (IAM) tem sido motivo de intenso debate nos últimos anos. Estima-se que, entre os pacientes com SAF definida, a freqüência de IAM seja de $4 \%$ a $20 \%(89)$.

Farsi et al. estudaram o binômio cardiopatia isquêmicaanticorpos anti-beta2-gpI. Vinte casos de angina instável, 17 casos de angina aos esforços e 40 controles sadios foram avaliados. O isotipos IgG e IgM, mas não IgA anti-beta2gpI, foram testados. Prevalência e titulação dos anticorpos foram mais expressivos no grupo com angina instável que em casos de angina aos esforços ${ }^{(90)}$.
Em outro estudo, as presenças de IgG anti-beta2-gpI e de aCL não conferiram risco de reestenose coronária após angioplastia, ao contrário do observado com anticorpos anti-LDL oxidado ${ }^{(91)}$.

Limaye et al. não relataram diferenças nos níveis de anticorpos anti-beta2-gpI em pacientes com doença coronariana comparativamente a controles sadios ${ }^{(92)}$. De forma similar, Brey et al. reportaram ausência de associação entre IgG anti-beta2-gpI e IAM $^{(93)}$.

Em recente estudo de caso-controles, nosso grupo avaliou a hipótese de que anticorpos anti-beta2-gpI se comportem como fatores de risco para IAM. Após análise multivariada, os dados indicaram que a presença de IgA antibeta2-gpI conferiu risco independente para o desfecho (razão de chances 3,4$)^{(94)}$.

\section{ANTICORPOS ANTI-BETA2-GPI, ANORMALIDADES NEUROLÓGICAS E ISQUEMIA CEREBRAL}

Em estudos in vitro ou em modelos animais, as alterações neurológicas relacionadas com anticorpos anti-beta2-gpI são dignas de referência. Segundo Caronti et al., soros de pacientes com SAF positivos para anti-beta2-gpI, assim como um anticorpo monoclonal anti-beta2-gpI, exibiram reatividade contra células neuronais e astrócitos. A ligação dos anticorpos, confirmada em imunofluorescência indireta, ocorreu independentemente da presença de aCL ${ }^{(95)}$.

Após imunização com um anticorpo monoclonal aCL, camundongos fêmeas da raça BALB/c, além de apresentarem aCL, anticorpos anti-beta2-gpI, trombocitopenia e reabsorção fetal, cursaram também com hiporreflexia, hiperatividade e incoordenação motora ${ }^{(96)}$.

A literatura envolvendo anticorpos anti-beta2-gpI e acidente vascular cerebral (AVC) isquêmico é ainda incipiente. De interesse, um anticorpo IgG anti-beta2-gpI (na ausência de aCL e AL) foi recentemente descrito em um adulto com infarto cerebral de origem obscura ${ }^{(97)}$.

Em um dos raros estudos no assunto, a presença de anticorpos anti-beta2-gpI foi avaliada em 259 pacientes com AVC isquêmico. A freqüência de IgG anti-beta2-gpI foi baixa em casos $(2,2 \%)$ e controles (1,9\%), o que não sugere um papel etiopatogênico para estes anticorpos no infarto cerebral ${ }^{(93)}$.

Também em 2001, Heinzlef et al. ${ }^{(98)}$ avaliaram a freqüência de IgG anti-beta2-gpI e de aCL em 242 idosos internados em conseqüência de infarto cerebral. Nenhum dos pacientes apresentou teste positivo para IgG anti-beta2-gpI. Outros isotipos anti-beta2-gpI não foram testados. Os dados corroboram uma baixa ou nula freqüência de IgG anti-beta2-gpI no infarto cerebral ${ }^{(89,98)}$. 
A possibilidade de que anticorpos anti-beta2-gpI confiram risco independente para infarto cerebral na fase aguda foi recentemente avaliada ${ }^{(99)}$. A associação do isotipo IgA anti-beta2gpI com isquemia cerebral aguda foi consistente em nossa casuística (razão de chances ajustada de 4,6). Infere-se, a partir deste dado, que estes anticorpos funcionem como fatores de risco independentes para AVC isquêmico em fase aguda ${ }^{(99)}$.

\section{REFERÊNCIAS}

1. Harris EN: Antiphospholipid syndrome. In: Klippel JH, Dieppe P, editors. Rheumatology. 2nd.ed, St. Louis:Mosby, 1-6, 1998.

2. Love PE, Santoro AS: Antiphospholipid antibodies: anticardiolipin and the lupus anticoagulant in systemic lupus erythematosus (SLE) and in non-SLE disorders. Ann Intern Med 112: 682-98, 1990.

3. Hughes GRV: The antiphospholipid syndrome: ten years on. Lancet 342: 341-3, 1993.

4. Hughes GRV, Harris EN, Gharavi AE: The anticardiolipin syndrome. J Rheumatol 13: 486-9, 1986.

5. Wilson WA, Gharavi AE, Koike T, et al: International consensus statement on preliminary classification criteria for definite antiphospholipid syndrome: report of an international workshop. Arthritis Rheum 42: 1309-11, 1999.

6. Asherson RA, Khamashta MA, Ordi-Ros J, et al: The "primary" antiphospholipid syndrome: major clinical and serological features. Medicine 68: 366-74, 1989.

7. Gharavi AE, Harris EN, Asherson RA, et al: Anticardiolipin antibodies: isotype distribution and phospholipid specificity. Ann Rheum Dis 46: 1-6, 1987.

8. Steinkasserer A, Cockburn DJ, Black DM, et al: Assignment of apolipoprotein $\mathrm{H}$ (beta2-gpI) to human chromossome 17g 23-qter determination of the major expression site. Cytogenet Cell Genet 60: 31-3, 1992.

9. McNeil HP, Simpson RJ, Chesterman CN, et al: Antiphospholipid antibodies are directed against a complex antigen that includes a lipid-binding inhibitor of coagulation beta2-gpI (apoliprotein $\mathrm{H}$ ). Proc Natl Acad Sci 87: 4120-4, 1990.

10. Galli M, Comfurious P, Maassen C: Anticardiolipin antibodies (ACA) directe not to cardiolipin but to a plasma cofactor. Lancet 335: 1544-7, 1990.

11. Hunt JE, McNeil HP, Morgan GJ, et al: A phospholipid-beta2-gpI complex is an antigen for anticardiolipin antibodies occurring in autoimmune disease but not with infection. Lupus 1: 75-81, 1992.

12. Gharavi AE, Sammaritano LR, Wen J, et al: Induction of antiphospholipid antibodies by immunization with beta2-gpI (apoliprotein H). J Clin Invest 90: 1105-9, 1992.

13. Gharavi AE, Sammaritano LR, Borastro JL, et al: Specificities and characteristics of beta2-gpI-induced antiphospholipid antibodies. J Clin Lab Med 125: 775-8, 1995.

14. Blank M, George J, Barak V, et al: Oral tolerance to low dose beta2gpI: immunomodulation of experimental antiphospholipid syndrome. J Immunol 161: 5303-12, 1998.

15. Kandiah DA, Krilis S: Beta2-gpI. Lupus 3: 207-12, 1994.

16. Polz E: Isolation of a specific lipid-binding protein from human serum by affinity chromatography using heparin-sepharose. In: Peeter
Em suma, IgA anti-beta-gpI são anticorpos dirigidos contra moléculas presentes na placa aterosclerótica. Epifenômenos ou não, estes anticorpos podem ser representativos do binômio auto-imunidade/aterosclerose em pacientes com $\mathrm{IAM}^{(94)}$ ou AVC isquêmico ${ }^{(99)}$. $\mathrm{O}$ acréscimo destes marcadores sorológicos à rotina laboratorial em pacientes com aterosclerose deve ser discutido em estudos futuros.

H, editor. Protides of biological fluids. Oxford:Pergamon, 817-20, 1979.

17. Borchman D, Harris EN, Pierangeli SS, et al: Interactions and molecular structure of cardiolipin and beta-2-gp1. Clin Exp Immunol 102: 373-8, 1995.

18. Schousboe I: Beta2-gpI: a plasma inhibitor of the contact activation of the intrinsic blood coagulation. Blood 66: 1086-91, 1985.

19. Nomura S, Fukuhara S, Komiyama Y, et al: Beta2-gpI and anticardiolipin antibody influence factor Xa generation but not factor $\mathrm{Xa}$ binding to platelet-derived microparticles [letter]. Thromb Haemost 71: 526-7, 1994.

20. Arnout J, Wittevrongel C, Vanrusselt M, et al: Beta2-gpI dependent lupus anticoagulants form stable bivalent antibody-beta2-gpI complexes on phospholipid surfaces. Thromb Haemost 79: 79-86, 1998.

21. Hojnik M, Gilburd, Ziporen L, et al: Anticardiolipin antibodies in infectious are heterogeneous in their dependency on beta2-gpI: analysis of anticardiolipin antibodies in leprosy. Lupus 3: 515-8, 1994.

22. Galli M, Ruggeri L, Barbui T: Differential effects of anti-beta2-gpI and antiprothrombin antibodies on the anticoagulant acitivity of activated protein C. Blood 91: 1999-2004, 1998.

23. Biasiolo A, Rampazzo P, Brocco T, et al: Anti-beta2-gpI-beta2-gpI immune complexes in patients with antiphospholipid syndrome and other immune diseases. Lupus 8: 121-6, 1999.

24. Mason NA, Harmer IJ, Mageed RA, et al: The BH1 idiotype defines a population of anticardiolipin antibodies closely associated with the antiphospholipid syndrome. Lupus 8: 234-9, 1999.

25. Pengo V, Biasiolo A, Fior MG: Autoimmune antiphospholipid antibodies are directed against a cryptic epitope expressed when beta2gpI is bound to a suitable surface. Thromb Haemost 73: 29-34, 1995.

26. Matsuura E, Igarashi $\mathrm{Y}$, Yasuda $\mathrm{T}$, et al: Anticardiolipin antibodies recognize beta2-gp1 structure altered by interacting with an oxygen modified solid phase surface. J Exp Med 179: 457-62, 1994.

27. Arvieux J, Roussel B, Jacob MC, et al: Measurement of antiphospholipid antibodies by ELISA using beta2-gpI as antigen. J Immunol Methods 143: 223-9, 1991.

28. Tincani A, Spatola L, Prati E, et al: The anti-beta2-gpI activity in human antiphospholipid syndrome sera is due to monoreactive low affinity autoantibodies directed to epitopes located on native beta2-gpI and preserved during species evolution. J Immunol 157: 5732-8, 1996.

29. Sheng Y, Kandiah DA, Krilis AS: Anti-beta2-gpI autoantibodies from patients with the "antiphospholipid" syndrome bind to beta2gpI with low affinity: dimerization of beta2-gpI induces a significant increase in anti-beta2-gpI antibody affinity. J Immunol 161: 2038-43, 1998.

30. Tincani A, Spatola L, Cinquini M, et al: Anti-beta2-gp1 antibodies: clinical significance. Lupus 7(suppl. 2): S107-9, 1998. 
31. Arvieux J, Regnault V, Hachulla E, et al: Heterogeneity and immunochemical properties of anti-beta2-gpI autoantibodies. Thromb Haemost 80: 393-8, 1998.

32. Santiago M, Rocha MC, Souza S, et al: Anticorpos anti-beta2-gp1 em pacientes com lúpus eritematoso sistêmico. Rev Bras Reumatol 40: 285-90, 2000.

33. Tsutsumi A, Ichikawa K, Matsuura E, et al: Heterogeneous behaviour of anti-beta2gp1 antibodies on various commercially available enzyme imunnoassay plates coated with beta2-gp1. J Rheumatol 27: 391-6, 2000.

34. Lewis S, Keil LB, Binder WL, et al: Standardized measurement of major immunoglobulin class (IgG, IgM, IgA) antibodies to beta2-gp I in patients with antiphospholipid syndrome. J Clin Lab Anal 12: 293-7, 1998.

35. Cucnik S, Ambrozic A, Bozic B, et al: Anti-beta2-gpI ELISA: methodology, determination of cut-off values in 434 healthy Caucasians and evaluation of monoclonal antibodies as possible international standards. Clin Chem Lab Med 38: 777-83, 2000.

36. Ichikawa K, Tsutsumi A, Atsumi T, et al: A chimeric antibody with the human gamma 1 constant region as a putative standard for assay to detect IgG beta2-gpI-dependent anticardiolipin and anti-beta2gpI antibodies. Arthritis Rheum 42: 2461-70, 1999.

37. Roubey RAS, Maldonado MA, Byrd SN: Comparison of an enzymelinked immunosorbent assay for antibodies to beta2-gpI and a conventional anticardiolipin immunoassay. Arthritis Rheum 39: 1606-7, 1996

38. McNally T, Mackie IJ, Machin SJ, et al: Increased levels of beta2gpI antigen and beta2-gpI binding antibodies are associated with a history of thromboembolic complications in patients with SLE and primary antiphospholipid syndrome. Br J Rheumatol 34: 1031-6, 1995.

39. Bruce IN, Clark-Soloninka CA, Spitzer KA, et al: Prevalence of antibodies to beta2-gpI in systemic lupus erythematosus and their association with antiphospholipid antibody syndrome criteria: a single center study and literature review. J Rheumatol 27: 2833-7, 2000.

40. Helbert M, Bodger S, Cavenagh J, et al: Optimising testing for phospholipid antibodies. J Clin Pathol 54: 693-8, 2001.

41. Balestrieri G, Tincani A, Spatola L, et al: Anti-beta2-gpI: a marker of antiphospholipid syndrome? Lupus 4: 122-30, 1995.

42. Arvieux J, Roussel B, Colomb MG: Anticorps antiphospholipids et anti-beta2-gpI. Ann Biol Clin Paris 52: 381-5, 1994.

43. Tinahones FJ, Cuadrado MJ, Khamasta MA, et al: Lack of crossreaction between antibodies to beta2-gp1 and oxidized LDL in patients with antiphospholipid sydrome. Br J Rheumatol 37: 746-9, 1998.

44. Matsuura E, Katahira T, Igarashi Y, et al: Beta2-gpI bound to oxidatively modified lipoproteins could be targeted by anticardiolipin antibodies. [abstract] Lupus 3: 314, 1994.

45. George G, Gilburd B, Langewitz P, et al: Beta2-gpI containing immunocomplexes in lupus patients: association with thrombocytopenia and lipoprotein (a) levels. Lupus 8: 116-20, 1999.

46. Viard JP, Amoura Z, Back JF: Association of anti-beta2-gp1 antibodies with lupus-type circulating anticoagulant and thrombosis in SLE. Am J Med 93: 181-6, 1992.

47. Sanfilippo SS, Khamashta MA, Atsumi T, et al: Antibodies to beta2gpI: a potential marker for clinical features of antiphospholipid antibody syndrome in patients with systemic lupus erythematosus. J Rheumatol 25: 2131-4, 1998.

48. Tubach F, Hayem G, Marchand JL, et al: IgG anti-beta2-gpI antibodies in adult patients with systemic lupus erythematosus: prevalence and diagnostic value for the antiphospholipid syndrome. J Rheumatol 27: 1437-43, 2000.

49. Shrivastava A, Dwivedi S, Aggarwal A, et al: Anticardiolipin and anti-beta2-gpI antibodies in Indian patients with systemic lupus erythematosus: association with the presence of seizures. Lupus 10: 45-50, 2001.

50. Aguirre V, Cuchacovich R, Barria L, et al: Prevalence and isotype distribution of antiphospholipid antibodies in Chilean patients with systemic lupus erythematosus. Lupus 10: 75-80, 2001.

51. Inanc M, Donohoe S, Ravirajan CT, et al: Anti-beta2-gpI, antiprothrombin and anticardiolipin antibodies in a longitudinal study of patients with systemic lupus erythematosus and the antiphospholipid syndrome. Br J Rheumatol 37: 1089-94, 1998.

52. Sebastiani GD, Galeazzi M, Tincani A, et al: Anticardiolipin and anti-beta2-gpI antibodies in a large series of European patients with systemic lupus erythematosus. Prevalence and clinical associations. European Concerned Action on the Immunogenetics of SLE. Scand J Rheumatol 28: 344-51, 1999.

53. Cucurull E, Espinoza LR, Mendez E, et al: Anticardiolipin and antibeta2-gpI antibodies in patients with systemic lupus erythematosus: comparisons between Colombians and Spaniards. Lupus 8: 134-41, 1999.

54. Gomez-Pacheco L, Villa AR, Drenkard C, et al: Serum anti-beta2$\mathrm{gpI}$ and anticardiolipin antibodies during thrombosis in systemic lupus erythematosus. Am J Med 106: 417-23, 1999.

55. Tsutsumi A, Matsuura E, Ichikawa K, et al: IgA class anti-beta2-gpI in patients with systemic lupus erythematosus. J Rheumatol 25: 74-8, 1998.

56. Tsutsumi A, Matsuura E, Ichikawa K, et al: Antibodies to beta2-gpI and clinical manifestations in patients with systemic lupus erythematosus. Arthritis Rheum 39: 1466-74, 1996.

57. Bertolaccini ML, Atsumi T, Escudero-Contreras A, et al: The value of IgA antiphospholipid testing for diagnosis of antiphospholipid (Hughes) syndrome in systemic lupus erythematosus. J Rheumatol 28: 2637-43, 2001.

58. Cucurull E, Gharavi AE, Diri E, et al: IgA anticardiolipin and antibeta2-gpI are the most prevalent isotypes in African American patients with systemic lupus erythematosus. Am J Med Sci 318: 55-60, 1999.

59. Lee SS, Cho ML, Joo YS, et al: Isotypes of anti-beta2-gpI antibodies: association with thrombosis in patients with systemic lupus erythematosus. J Rheumatol 28: 520-4, 2001.

60. Lakos G, Kiss E, Regeczy N, et al: Isotype distribution and clinical relevance of anti-beta2-gpI antibodies: importance of $\operatorname{IgA}$ isotype. Clin Exp Immunol 117: 547-9, 1999.

61. Detkov, Gil-Aguado A, Lavilla P, et al: Do antibodies to beta2-gpI contribute to better characterization of the antiphospholipid syndrome? Lupus 8: 430-8, 1999.

62. Tektonidou MG, Ioannidis JP, Boki KA, et al: Prognostic factors and clustering of serious clinical outcomes in antiphospholipid syndromes. QJM 93: 523-30, 2000.

63. Faden D, Tincani A, Tanzi P, et al: Anti-beta2-gpI antibodies in a general obstetric population: preliminary results on the prevalence and correlation with pregnancy outcome. Anti-beta2-gpI antibodies are associated with some obstetric complications, mainly preeclampsiaeclampsia. Eur J Obstet Gynecol Reprod Biol 73: 37-42, 1997.

64. Franklin RD, Hollier N, Kutteh WH: Beta2-gpI as a marker of antiphospholipid syndrome in women with recurrent pregnancy loss. Fertil Steril 73: 531-5, 2000. 
65. Gris JC, Quere I, Sanmarco M, et al: Antiphospholipid and antiprotein syndromes in non-thrombotic, non-autoimmune women with unexplained recurrent primary early foetal loss: The Nimes Obstetricians and Haematologists Study - NOHA. Thromb Haemos 84: 228-36, 2000.

66. Lynch A, Byers T, Emlen W, et al: Association of antibodies to beta2gpI with pregnancy loss and pregnancy-induced hypertension: a prospective study in low-risk pregnancy. Obstet Gynecol 93: 193-8, 1999.

67. Lee RM, Branch DW, Silver RM: Immunoglobulin A anti-beta2gpI antibodies in women who experience unexplained recurrent spontaneous abortion and unexplained fetal death. Am J Obstet Gynecol 185: 748-53, 2001.

68. Lee RM, Emlen E, Scott JR, et al: Anti-beta2-gpI antibodies in women with recurrent spontaneous abortion, unexplained fetal death, and antiphospholipid syndrome. Am J Obstet Gynecol 181: 642-8, 1999.

69. Zanon E, Prandoni P, Vianello F, et al: Anti-beta2-gpI antibodies in patients with acute venous thromboembolism: prevalence and association with recurrent thromboembolism. Thromb Res 96: 269-74, 1999.

70. Sands JJ, Nudo AS, Moore KD, et al: Antibodies to prothrombin, factor $\mathrm{V}$, and beta2-gpI and vascular access thrombosis. ASAIO J 47: 507-10, 2001.

71. Martinuzzo ME, Pombo G, Forastiero RR, et al: Lupus anticoagulant, high levels of anticardiolipin and anti-beta2-gpI antibodies are associated with chronic thromboembolic pulmonary hypertension. J Rheumatol 25: 1313-9, 1998.

72. Liozon E, Roussel V, Roblot P, et al: Absence of anti-beta2-gpI antibodies in giant cell arteritis: a study of 45 biopsy-proven cases. Br J Rheumatol 37: 1129-31, 1998.

73. Koutroubakis IE, Petinaki E, Anagnostopoulou E, et al: Anticardiolipin and anti-beta2-gpI antibodies in patients with inflammatory bowel disease. Dig Dis Sci 43: 2507-12, 1998.

74. Kang HJ, Lee YW, Han SH, et al: Anticardiolipin and anti-beta2gpI antibodies in Behçet disease. J Korean Med Sci 13: 400-4, 1998.

75. McNally T, Purdy G, Mackie IJ, et al: The use of an anti-beta2-gpI assay for discrimination between anticardiolipin antibodies associated with infection and increased risk for thrombosis. Br J Haematol 91: 471-3, 1995.

76. Santiago MB, Martinelli R, Ko A, et al: Anti-beta2-gpI and anticardiolipin antibodies in leptospirosis, syphilis and kala-azar. Clin Exp Rheumatol 19: 425-30, 2001.

77. De Larranaga GF, Forastiero RR, Martinuzzo ME, et al: High prevalence of antiphospholipid antibodies in leprosy: evaluation of antigen reactivity. Lupus 9: 594-600, 2000.

78. Ioannidis JP, Tektonidou MG, Vlachoyiannopoulos PG, et al: HLA associations of anti-beta2-gpI response in a Greek cohort with antiphospholipid syndrome and meta-analysis of four ethnic groups. Hum Immunol 60: 1274-80, 1999.

79. Galeazzi M, Sebastiani GD, Tincani A, et al: HLA class II alleles associations of anticardiolipin and anti-beta2-gpI antibodies in a large series of European patients with systemic lupus erythematosus. Lupus 9: 47-55, 2000.

80. Arnett FC, Thiagarajan P, Ahn C, et al: Associations of anti-beta2gpI with class II alleles in three ethnic groups. Arthritis Rheum 42: 268-74, 1999.
81. Wick G, Xu Q: Atherosclerosis: an autoimmune disease. Exp Gerontol 34: 559-66, 1999.

82. Ross R: Atherosclerosis: an inflammatory disease. N Engl J Med 340: 115-26, 1999.

83. Romero FI, Amengual O, Atsumi T, et al: Arterial disease in lupus and secondary antiphospholipid syndrome: association with antibeta2-gpI antibodies but not with antibodies against oxidized lowdensity lipoprotein. Br J Rheumatol 37: 883-8, 1998.

84. Amengual O, Atsumi K, Khamashta MA, et al: Antibodies against oxidized low-density lipoprotein in antiphospholipid syndrome. $\mathrm{Br}$ J Rheumatol 36: 964-8, 1997.

85. Romero FI, Atsumi T, Tinahones FJ, et al: Autoantibodies against malondialdehyde-modified lipoprotein (a) in antiphospholipid syndrome. Arthritis Rheum 42: 2606-11, 1999.

86. George J, Harats D, Gilburd B, et al: Immunolocalization of beta2gpI (apolipoprotein $\mathrm{H}$ ) to human atherosclerotic plaques: potential implications for lesion progression. Circulation 99: 2227-30, 1999.

87. George J, Afek A, Gilburd B, et al: Induction of early atherosclerosis in LDL-receptor-deficient mice immunized with beta2-gpI. Circulation 98: 1108-15, 1998.

88. Afek A, George J, Shoenfeld Y, et al: Enhancement of atherosclerosis in beta2-gpI-immunized apoliprotein E-deficient mice. Pathobiology 67: 19-25, 1999.

89. O'Vaarala: Antiphospholipid antibodies and myocardial infarction. Lupus S2 132-34, 1998.

90. Farsi A, Domeneghetti MP, Fedi S, et al: High prevalence of antibeta2-gpI antibodies in patients with ischemic heart disease. Autoimmunity 30: 93-8, 1999.

91. George J, Harats D, Bakshi E, et al: Anti-oxidized low density lipoprotein antibody determination as a predictor of reestenosis following percutaneous transluminal coronary angioplasty. Immunol Lett 68: 263-6, 1999.

92. Limaye V, Beltrame J, Cook R, Gillis D, Pile K: Evaluation of antibodies to $\mathrm{b} 2$-glycoprotein 1 in the causation of coronary atherosclerosis as part of the antiphospholipid syndrome. Aust NZ J Med 29: 789-93, 1999.

93. Brey RL, Abbott RD, Curb D, Sharp DS, Ross GW: b2-glycoprotein 1-dependent anticardiolipin antibodies and risk of ischemic stroke and myocardial infarction. Stroke 32: 1701-06, 2001.

94. Ranzolin A, Norman GL, Manenti E, Bodanese LC, Von Mühlen CA, Staub HL: Antibodies to beta2-glycooprotein I as risk factors for acute myocardial infarction. Arq Bras Cardiol, 2003. (In press).

95. Caronti B, Calderaro C, Alessandri C, et al: Serum anti-beta2-gpI antibodies from patients with antiphospholipid antibody syndrome bind central nervous system cells. J Autoimmun 11: 425-9, 1998.

96. Ziporen L, Shoenfeld Y, Levy Y, et al: Neurological dysfunction and hyperactive behaviour associated with antiphospholipid antibodies: a mouse model. J Clin Invest 100: 613-9, 1997.

97. Chen WH, Liu JS: An unusual increase of blood anti-beta2-gpI antibody but not antiphospholipid antibody in cerebral ischemia: a case report. Angiology 52: 149-54, 2001.

98. Heinzlef $\mathrm{O}$, Abuaf N, Cohen A, et al: Recurrent stroke and vascular events in elderly patients with anticardiolipin antibodies: a prospective study. J Neurol 248: 373-9, 2001.

99. Staub HL, Norman GL, Crowther T, et al: Antibodies to the atherosclerotic plaque components beta2-glycoprotein and heatshock proteins as markers of acute cerebral ischemia. Arq Neuropsiquiatr, 2003. (In press). 